\title{
Mosaicos hispano-romanos con representaciones de musas
}

\author{
Hispano-roman mosaics with representations of muses
}

\author{
M. P. SAn Nicolás PedRaZ*
}

\begin{abstract}
RESUMEN ABSTRACT
Se estudian los mosaicos hispanosromanos con representaciones de musas que pertenecen a las dos categorías de:

- Busto, identificadas o no con su nombre $o$ atributos

- Cuerpo entero, solas o acompañadas de Apolo o poetas/sabios

This paper examines mosaics from Roman Hispania with images of Muses. These representations are classified into two main categories:

- Busts images, identified or not, with her names and attributes.

- Whole body images, with or without Apollo or poets/wise men.
\end{abstract}

\section{PALABRAS CLAVE: KEYWORDS:}

Mosaicos, musas, atributos, Apolo, poetas, sabios.

Roman mosaics, Muses, attributes, Apollo, poets, wise men.

El tema de las musas tiene lugar en la producción de bajorrelieves y sobre todo de los sarcófagos de los siglos III $^{1}$, siendo frecuente su representación en la musivaria romana ${ }^{2}$, como consecuencia de la filosofía neoplatónica en la cual las musas presiden los banquetes de los filósofos (Plut. Banquete 21). Según Plutarco el objetivo de las musas no son los instrumentos (cítara, flauta...) sino la educación de las costumbres y el dominio de las pasiones a través de sus cantos armoniosos, es decir la cultura o Mousiké. Platón (Banq. 187e), situaba bajo el patronazgo de Urania y de Polimnia todas las actividades culturales, la primera como inspiradora

* UNED. Dep. Prehistoria y Argueología. Email. psan@geo.uned.es

1 R. TURCAN, Les sarcophages romaniza represéntations dionysiaques, Paris 1966, 441 y ss.

2 J. LANCHA y L. PADUANO FAEDO, Mousa, Mousai/Musae, LIMC VII, 1013-1059; THEOPHILIDOU Die Musenmosaiken der römischen Kaiserzeit, TZ47, 1984; J. LANCHA, Mosaïque et culture en occidente Dans I occident romain, I-IV siècle, Roma 1997, 318-324. 
de las formas superiores y la segunda de las formas vulgares del amor. Para Martianus Capella $(2,126)$, filólogo africano del siglo V, la esperanza de alcanzar la inmortalidad a través del conocimiento total de las ciencias, de las nueve disciplinas enciclopédicas que patrocinan las Musas, es la que se encuentra en la religión de las musas tal como proclama Talía al final de los cantos por los cuales cada musa invita a la Filología a recorrer sin ausentarse las nueve órbitas celestes. La religión de las musas abre las puertas del cielo a los mortales porque es a la vez sabiduría y elocuencia, dispensadora del saber y de la gloria dada por la inmortalidad. El concepto de la heroización por la ciencia, ligado al culto de las Musas, nace con el pitagonismo y se extiende por todo el pensamiento filosófico griego ${ }^{3}$

Las musas eran hijas de Zeus/Júpiter y Mnemósine, la Memoria, y nacieron, tras nueve noches de amor, en Pieria (Tracia) (Hes. Teog. 53-61), al pie del monte Olimpo, por lo que a veces se las denomina Piérides. Otra versión del sobrenombre está tomada de la victoria de las Musas al convertir a las Piérides, hijas de Piero de Macedonia, en urracas (Ovid. Met. 294-317 y 663-678). La tradición les atribuye diferentes residencias, una en el monte de Helicón, en Beocia, otra en el monte Parnaso, en la Fócide por su asociación con Apolo, dios de la música y poesía, y lugar donde presidía los concursos de las Musas, y una tercera morada en el Olimpo (Hes. Teog. 62ss). El número de nueve figura por primera vez en Homero (Od. XXIV 60) y sus nombres, que se impondrán en época clásica, no aparecen antes de Hesíodo (Teog. 75-79): Clío (Gloriosa), musa de la historia (Luc. Imag. 16; Anth. Graeca IX, 505), Euterpe (Deliciosa) de la música y canto (Luc. Imag. 16; Anth. Graeca V, 504-505; Ant. Lat. 88, 664), Talía (Floreciente) de la comedia, Melpómene (Celebrada en cantos) musa de la tragedia (Luc. Imag. 16; Anth. Graeca V, 504; Ant. Lat. 88, 664), Terpsícore (Deliciosa danzante) de la danza, Erato (Adorable) musa de la poesía erótica, Polimnia (Cantora de himnos) de la pantomima o la danza (Luc. Imag. 16; Anth. Graeca V, 504; Ant. Lat. 88, 664), Urania (la Celeste) musa de la Astronomía (Luc. Imag. 16; Anth. Graeca IX, 505), Calíope (Bella voz) protectora de la actividad poética (Luc. Imag. 16; Anth. Graeca V, 504; Ant. Lat. 88, 664).

Los atributos de las musas pueden estar o no representados y a veces son intercambiables, pero por regla general caracterizan a cada una de ellas. Así Talía y Melpómene portan la máscara de teatro, Caliope y Clío el dypthichon o uolumen, Terpsícore y Euterpe la lira o el aulos ${ }^{4}$.

En Hispania el número de mosaicos con representaciones de musas es considerable en comparación con otras provincias del Imperio, existen hasta el momento un total de catorce ejemplares. Aparecen tanto en las domus como en las viIlae, decorando diferentes espacios conviviales, además tienen la particularidad que se han encontrado no solo pavimentando los suelos sino también ornamen-

3 J. PRÉAUX, Le culte des Mouses chez Martianus Capella, Mélanges P. Boyancé, Roma 1974, 610-611; P. BOYANCÉ, Le culte des Mouses chez les philosophes grecs, Paris 1993, 231 ss.

${ }^{4}$ Para los atributos de las musas $c f$. L. PADUANO FAEDO, I sarcofagi romani con Muse, ANRW II, 12,2, 1981, 71-77; J. LANCHA, Mosaïque et culture...318-324. 
tado paredes. Siguiendo la clasificación de Parlasca ${ }^{5}$, se distinguen tres esquemas compositivos diferentes: bustos de musas en compartimentos separados (círculos, rectángulos, ángulos), musas de pie y musas acompañadas de poetas/sabios. La cronología de estos mosaicos abarca desde el siglo II hasta el IV.

${ }^{*}$ Representaciones de musas en forma de bustos, identificadas o no con sus nombres y por algún atributo característico; existen seis ejemplares.

El mosaico de circo de Itálica, del siglo IV, hoy perdido, está compuesto por una orla con $36 / 48$ cuadros con distintas decoraciones geométricas y florales y un campo central con un tapiz en $U+T$, cuyo espacio en $U$ tiene 36 medallones distribuidos en dos filas que han sugerido una composición ortogonal de círculos contiguos y tangentes. Se conoce por un detallado dibujo, entre otros, de Alexandre Laborde, en donde figuraban las nueve musas, en busto, con sus nombres en latín y el rostro ligeramente vuelto y altos peinados recogidos con plumas de las Piéri$\operatorname{des}^{6}$, dentro de medallones que están enmarcados alternativamente mediante coronas de laurel y coronas en forma entoldada con decoración de línea de ovas truncadas y de puntas de lanza adyacentes ${ }^{7}$. De ellas se conservan Terpsichore con una cetra (TREPSICHORE), Erato con ramo de laurel (ERATO), Polimnia con lira (POLYPNIA), Clío (CLIO), Euterpe (EUTERPE) y Urania (URANIA) no conservan sus atributos y en el medallón de Calíope existe un dypthichon de cera o uolumen y su nombre (KALIOPE), de Talía solo se conserva la máscara y Melpómene está perdida totalmente (Fig. 1). Aunque tradicionalmente este pavimento se ha ubicado en un complejo termal, actualmente I. Mañas ha sugerido por su diseño, que pavimentaría un triclinium.

En el mosaico de Moncada (Valencia), del siglo III, localizado fortuitamente en $1923^{8}$, aparecen las imágenes de las nueve musas ocupando una amplia superficie un tanto desplazada del centro del conjunto. Están dispuestas en cuadrículas delimitadas por cenefas sogueadas, en bustos, tocadas con plumas y con sus nombres en latín como en el mosaico anterior. De izquierda a derecha: Melpómene (MELPOMINI), con la máscara trágica (Tragedia); Talía (TALIA), con la máscara cómica y el pedum (Comedia); Euterpe (HEVTERPE), con la flauta o aulós (Música); Terpsícore (TERPICORE), con la lira (Danza); Clío (el nombre se ha perdido),

5 K. PARLASCA, Die römische Mosaiken in Deutschland, Berlín 1959, 141-143.

6 A. BLANCO, Mosaicos romanos de Itálica (I), CMRI II, Madrid 1978, 43, lám. 61-73; S. CELESTINO, Mosaicos perdidos de Itálica, Habis 8, 1977, 375-381; G. LÓPEZ MONTEAGUDO, Otras mitologías, in P. LEÓN (coord.), Arte romano de la Bética. Mosaico. Pintura. Manufacturas, Fundación FocusAbengoa, Sevilla 2010, 148-151, fig. 188; I. MAÑAS ROMERO Mosaicos romanos de Itálica (II), CMRI XIII, Madrid 2011, 86-90, lám. XXXII, figs. 185, 187 y 188 (con toda la bibliografía anterior).

7 I. BALMELLE et alii, Le décor géométrique de la mosaïque romaine I. Répertoire graphique et descriptif des compositions linéraires et isotropes, Paris 2002, 101a.

8 A. BALIL y T. MAÑANES, Mosaico con representaciones de las nueve Musas, hallado en Moncada (Valencia), Estudios sobre mosaicos romanos, VII SA, Valladolid 1980, ID BSEAA XLV, 1979, 1930 J. GÓMEZ PALLARÉS, Edición y comentario de las inscripciones sobre mosaicos de Hispania. Inscripciones no cristianas, Roma 1997, 159- 160, lám. 67; T. PASIES OVIEDO, Pavimentos musivos de época romana en la Comunidad Valenciana. Tratamientos y problemáticas asociadas a su conservación y restauración. Tesis Doctoral, Valencia 2004, 222-229 (recoge toda la bibliografía anterior). 


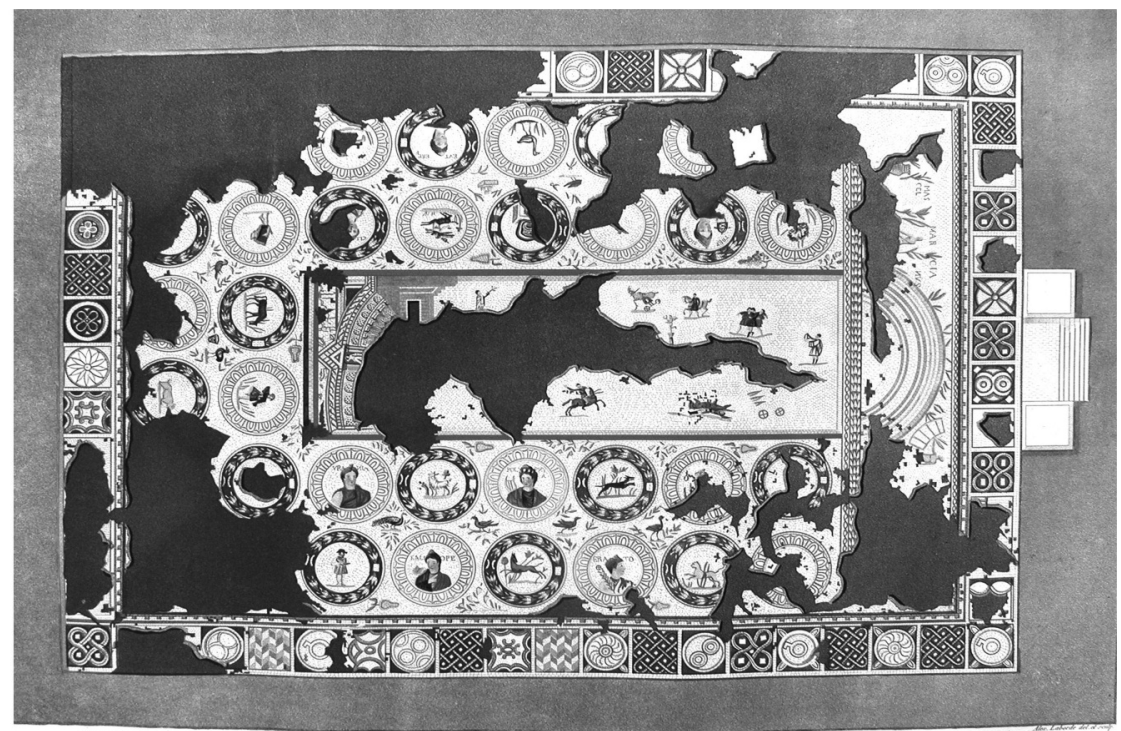

PLAN GÉNÉRAL DEL MOSAYCO IDE ITALICA

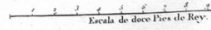

Fig. 1. Mosaico de Itálica. Siglo IV

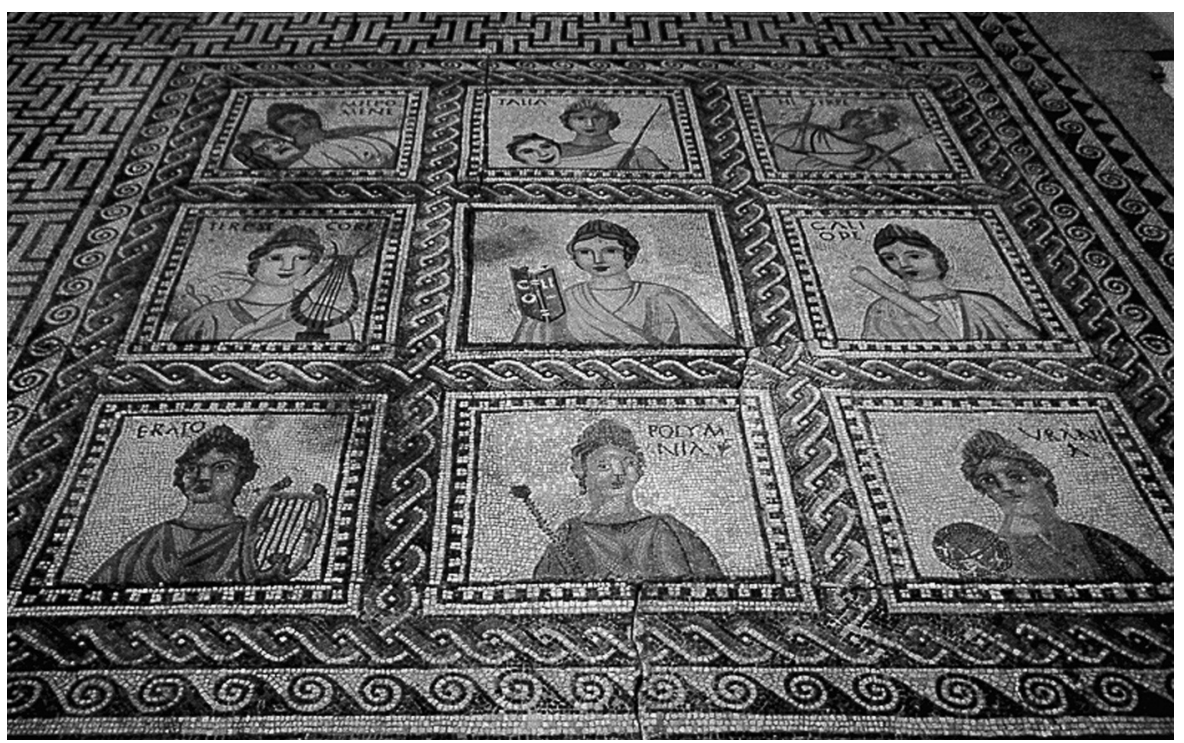

Fig. 2. Mosaico de Moncada, Valencia. Siglo III (Foto de G. López Monteagudo) 


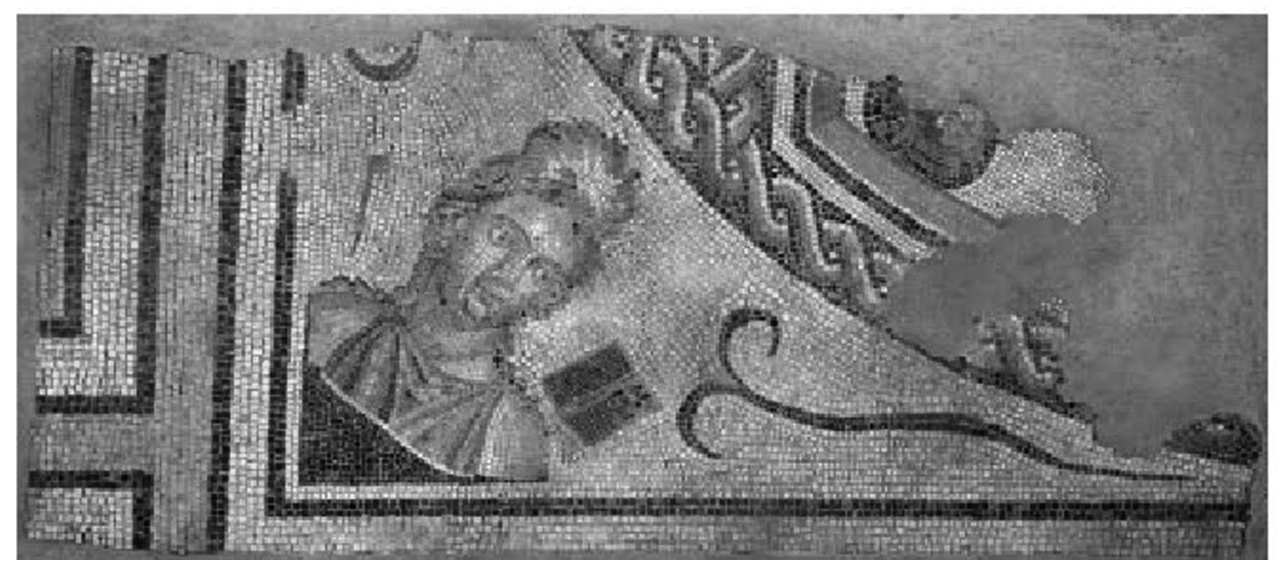

Fig. 3. Detalle del Mosaico de Caesaraugusta. Siglo II

con el uolumen abierto (Historia); Calíope (solo se conserva la terminación PE) (Poesía épica); Erato (ERATO), con la cítara (Poesía erótica); Polimnia (POLYMNIA), con el sceptrus (Lírica); y Urania (VRANIA), con la esfera o globo celeste (Astronomía). El lado izquierdo y superior de esta composición musivaria lo ocupa una zona en escuadra decorada por motivos geométricos que dibujan esvásticas dextrógiras y levógiras, resultantes de la combinación de paletones de llave simple, y todo el conjunto va enmarcado por un filete negro seguido de una banda formada por dientes de sierra y postas. (Fig. 2)

La misma composición con las musas dispuestas en cuadrículas aparece en el mosaico de las Nueve Musas de Trier, del siglo III $^{9}$.

En un fragmento del mosaico del triclinium de la Casa de Orfeo, del siglo II, localizado en la calle Murallas romanas y Plaza de Cesaraugusto, Zaragoza ${ }^{10}$, y que se conserva en el Museo Arqueológico de dicha localidad, se aprecia, en uno de los ángulos del cuadrado que inscribiría el emblemata circular el busto de la musa Clío, anepígrafa, con túnica y diadema de plumas, mirando a la derecha y flanqueada respectivamente por un stylus o calamus y unas tablillas de cera para escribir (diptychon) (Fig. 3). En uno de los hexágonos, muy destruido, del emblemata aparece restos de una esfera, símbolo de Urania (Fig. 4), mientras que otro se conserva el busto de un sátiro (Fig. 5).

9 K. PARLASCA, Die römische Mosaiken..., 32 ss, lám. 31-33 ; E. THEOPHILIDOU, Die Musenmosaiken ..., 271 ss., $\mathrm{n} \times 29$.

${ }^{10} \mathrm{~F}$. de A. ESCUDERO, Mosaico con musas de la "Casa de las Murallas" de Zaragoza, Anas 1112, 1998-1999, 109-132, láms. 2,2 y 5,2. 


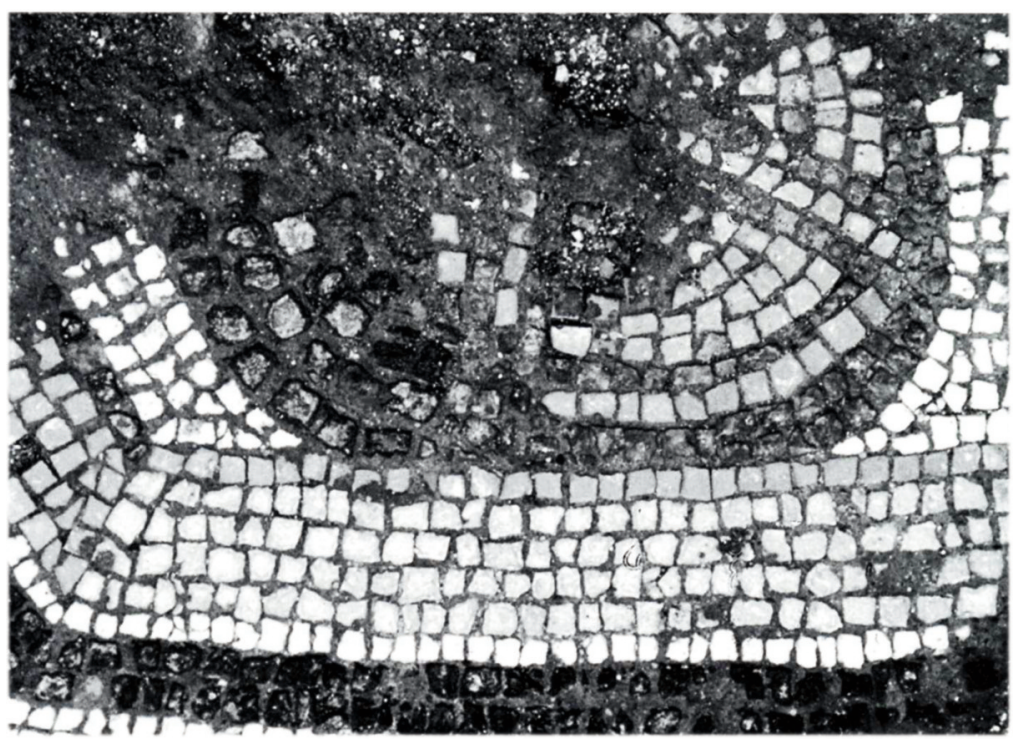

Fig. 4. Detalle del Mosaico de Caesaraugusta. Siglo II (Foto de F, de A. Escudero)

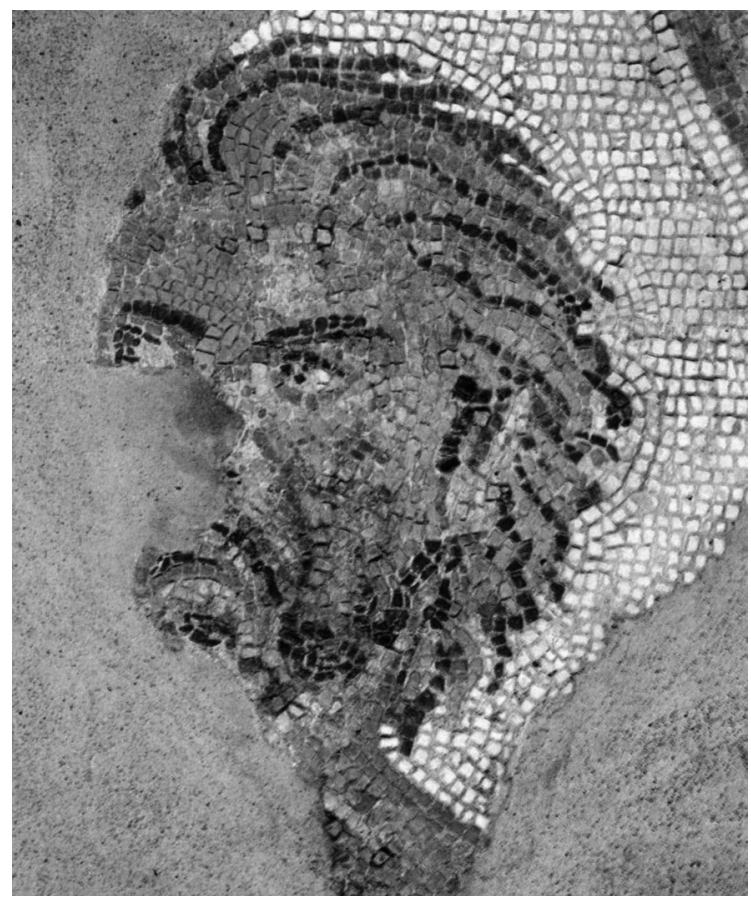

Fig. 5. Detalle del Mosaico de Caesaraugusta. Siglo II (Foto de F. de A. Escudero) 
La asociación de las Musas con temas dionisiacos es frecuente en los sarcófagos y en algunos mosaicos, como ocurre en los ejemplares de Cos, Gerasa, Colonia y Antioquía ${ }^{11}$. Según R. Turcan ${ }^{12}$, Dionisos es cantado por los poetas griegos como el Cosmokrator que dispensa a la oikouméne la vida civilizada; esta figura helenística del héroe colonizador y vencedor de la fuerza bruta y el desorden, que somete a todos los pueblos salvajes es recogida en época romana y reconocida en la Virtus que dispensa a los hombres la Felicitas ${ }^{13}$. Para $\mathrm{H}$. Joyce ${ }^{14}$ esta asociación entre las musas y los temas dionisiacos estaría justificada por ser Dionisos una divinidad conectada con el teatro y en este contexto el dios era un compañero frecuente de las musas ${ }^{15}$.

En la villa de Els Munts, en Altafulla, Tarragona, se han encontrado tres mosaicos de pared, fechados en el siglo II y que sin duda estarían ubicados en salas de prestigio ${ }^{16}$, con las representaciones de musas en busto y también anepígrafas, que se conservan en el Museo Arqueológico de Tarragona, realizados en opus vermiculatum y fijados sobre un soporte cerámico como marco, unicum en la musivaria romana ${ }^{17}$.

En uno de ellos aparece Euterpe con tocado de pluma y los auloi. El soporte es cuadrangular por los dos lados y conserva restos de pintura en el marco (Fig. 6).

En otro mosaico se encuentra representada Talía, también con plumas de las Piérides y con la máscara teatral de la comedia en la parte inferior derecha. El soporte es cuadrado en el exterior y circular en el interior (Fig. 7).

El tercer cuadro de la villa de Els Munts presenta el busto, según los diferentes autores que han tratado el tema, de Mnemósine/ Polimnia/ Apolo, con diadema blanca y sin atributo $^{18}$ (Fig. 8). Por otra parte existe un cuarto cuadro que M. Durán señala que podría identificarse con Apolo en vez del retrato del propietario de la villa ${ }^{19}$, en este caso el conjunto de los diferentes cuadros de los mosai-

11 G. LÓPEZ MONTEAGUDO y M.P. SAN NICOLÁS PEDRAZ, Los sabios y la ciencia en los mosaicos romanos, L Africa Romana XI, 1996, 80.

12 R. TURCAN, Les sarcophages romains à représentations dionysiaques, Paris 1966, $441 \mathrm{ss.}$

13 G.W. BOWERSOCK, L ellenismo nel mondo tardoantico, Quadrante Laterza, Roma 1992, 70-76; J. BERMEJO TIRADO, El resurgimiento tardorromano de lo dionisiaco desde una perspectiva social, Latomus $70,2011,755-771$.

${ }^{14}$ H. JOYCE, A Mosaic from Gerasa in Orange, Texas, and Berlin, RM 87, 1980, 319 ss.

${ }^{15}$ En algunos mosaicos se aprecia la conexión de Dionisos como divinidad del teatro, cf. M. P. SAN NICOLÁS PEDRAZ, Ariadna, entre el desengaño y el amor, in M.L. Neira (coord. y ed.), Representaciones de mujeres en los mosaicos romanos y su impacto en el imaginario de estereotipos femeninos, CVC, Madrid 2011, 49-51.

${ }_{16}$ F. TARRATS et alii, Excavaciones a I Área residencial de la Vil.la romana dels Munts (Altafulla, Tarragonès, Empuries 51, 1999, 197-225 (216)

17 M. DURÁN PENEDO, Nuevos mosaicos de la villa dels Munts en Altafulla, Tarragona. Apreciaciones iconográficas, Monte Catano 3, 2000, 35-51.

18 Para la mayoría de los autores esta figura sin atributos sería Mnemósine, madre de las musas, pero para Durán sería la musa Polimnia y para Balty Apolo, cf. VV.AA. Mosaico Romano de Mediterráneo, Madrid 2001, 170-171.

${ }_{19}$ M. DURÁN PENEDO, Las preferencias iconográficas de los clientes refinados hispano-romanos, al encargar los mosaicos de sus viviendas, Monte Catano 9, 2007, 112, fig. 21. 
cos seguirían la versión homérica (II. 1604), en donde se menciona que en el banquete de los dioses las Musas cantaban junto a Apolo, como parece ocurrir en el mosaico de Itálica y en el de Noheda (Cuenca), que posteriormente analizaremos.

En Montemayor (Córdoba), la antigua Ulia, aparecieron dos fragmentos de mosaico con musas, hoy perdidos, del siglo IV20. En uno de ellos figuraba la cabeza y hombros de Euterpe, identificada con su nombre en latín; en el otro fragmento se conservan dos cabezas femeninas. Posiblemente estas tres Musas estarían representadas en bustos como en los anteriores mosaicos.

${ }^{*}$ Representaciones de musas en forma de cuerpo entero, solas, acompañadas de Apolo o poetas/sabios, identificadas o no por sus nombres y por algún atributo característico ${ }^{21}$.

En el mosaico de la pompa triumphalis de Dionisos de la villa de Torre de Palma (Portugal), fechado en época constantiniana ${ }^{22}$, (Fig. 9) aparece en un cuadro

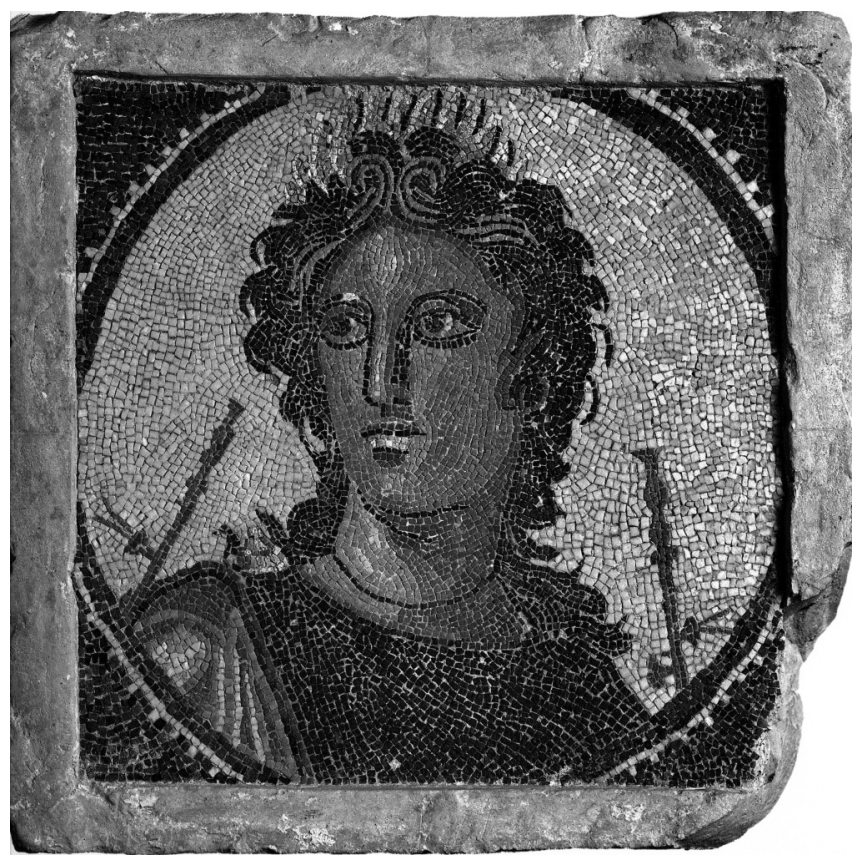

Fig. 6. Mosaico de Altafulla, Tarrragona. Siglo III

20 J.M. BLÁZQUEZ, Mosaicos romanos de Córdoba, Jaén y Málaga, CMRE III, Madrid 1981, 56.; G. LÓPEZ MONTEAGUDO y M.P. SAN NICOLÁS PEDRAZ, Reflejos de la vida intelectual en la musivaria romana, Espacio, Tiempo y Forma II/7, 1994, 249-308; ID. Los sabios y la ciencia... 71-110.

21 G. LÓPEZ MONTEAGUDO y M.P. SAN NICOLÁS PEDRAZ, Reflejos de la vida intelectual..., 249-308; ID. Los sabios y la ciencia..., 71-110

22 J.M. BLÁZQUEZ, Los mosaicos romanos de Torre Palma (Monforte, Portugal), AEspA 53, 1980, 132-134, fig. 3. 


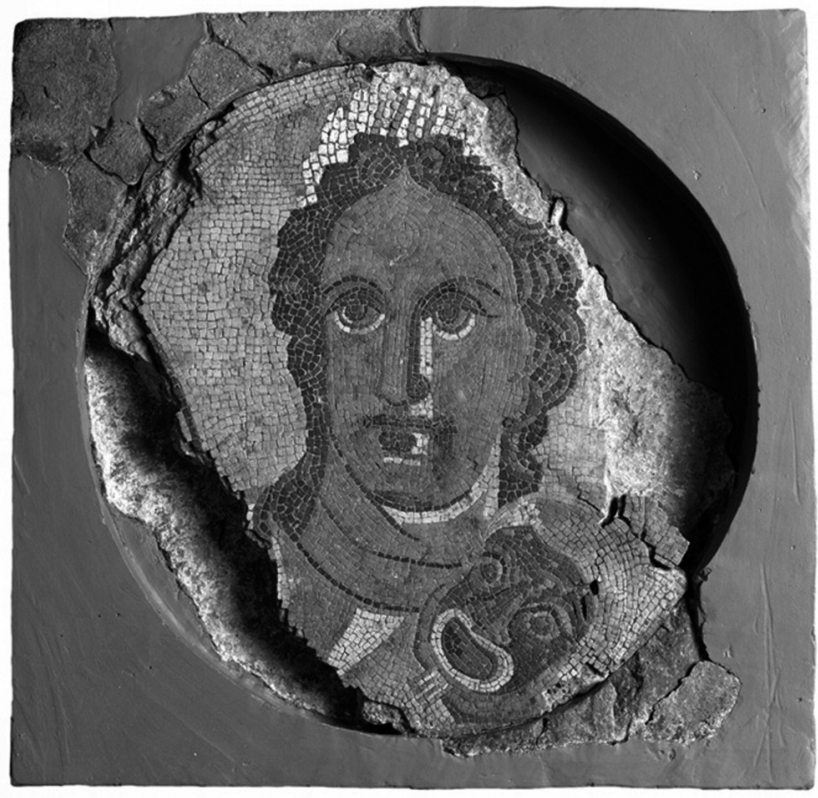

Fig. 7. Mosaico de Altafulla, Tarrragona. Siglo III

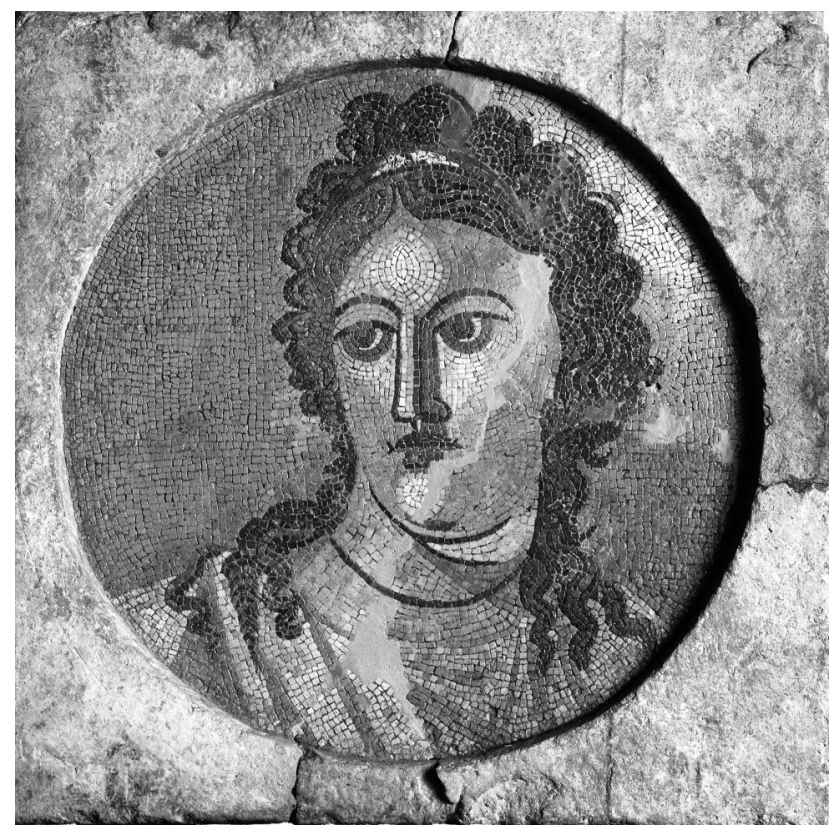

Fig. 8. Mosaico de Altafulla, Tarrragona. Siglo III 


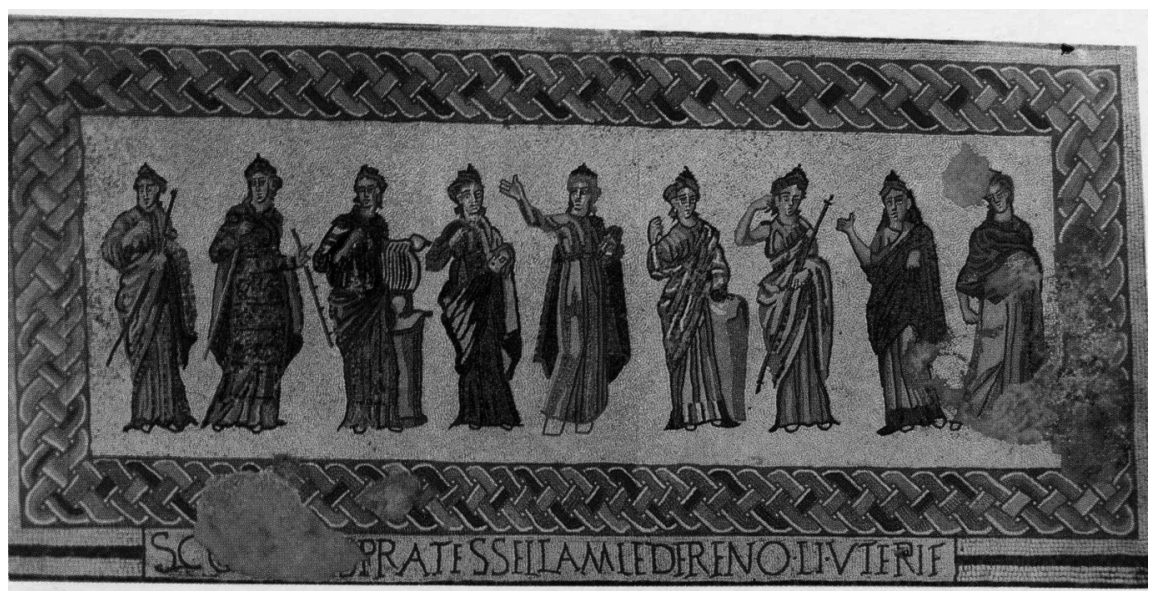

Fig. 9. Mosaico de Monforte, Portugal. Siglo II-III (Foto de G. López Monteagudo)

rectangular solamente las nueve Musas de frente, en pie, sin letreros identificativos, con altos peinados recogidos con plumas de las Piérides y visten túnicas y pallas: Caliope con cetro, Euterpe, Erato, Talía, Melpómene, Clio, Urania con una vara, Polimnia, Terpsícore. En la parte inferior del cuadro se encuentra la inscripción latina: SCO...PARA TESSELAMLEDERE NOLI. VTERIF(elix), que tiene que ver con la limpieza del mosaico.

Figuras de musas representadas posiblemente con Apolo, existen dos ejemplares.

En el mosaico de Itálica, del siglo III, hoy perdido y que se conoce gracias a un dibujo de Demetrio de los Ríos realizado en 1872, aparecía una figura central, de cuerpo entero, muy deteriorada, posiblemente Apolo, rodeada de las nueve Musas, de pie, sin letreros identificativos pero con algunos atributos y posiblemente en orden numérico como aparecen en la obra de Hesiodo (Teog. 77-79) (Fig. $10)^{23}$. De derecha a izquierda: Clío vestida con chiton y manto sobre los hombros; Euterpe con chiton y manto, con la flauta o tibia; Talía con palla o vestido teatral y manto, portando la máscara; Melpómene; Terpsícore; Erato con una cetra, Polimnia sin atributo, Urania con chiton, manto y el radius o compás; Caliope con el dypthichon o uolumen. Si tenemos en cuenta la figura central deteriorada de Apolo, el pavimento seguiría la versión homérica (II. 1604) (supra). El mismo orden aparece posteriormente en Ausonio (De nomine Musarum 1-11).

${ }^{23}$ En el dibujo las musas aparecen tocadas con corona de laurel, pero posiblemente sea un error del dibujante puesto que casí siempre en sus representaciones aparecen con la corona de plumas de las Piérides, cf. M.P. SAN NICOLÁS PEDRAZ, Sobre el mosaico perdido de Galatea, Itálica (Sevilla), Arte, sociedad, economía y religión durante el Bajo Imperio y la Antigüedad Tardía VIII, Murcia 1991, 531-540; J. LANCHA, Mosaïque et culture..., 193-194 I. MAÑAS, Pavimentos decorativos de Itálica (Santiponce, Sevilla), Tesis Doctoral, Univ. Complutense, Madrid 2008 (se recoge la bibliografía anterior); G. LÓPEZ MONTEAGUDO, Otras mitologías..., 143-144, fig. 182. 


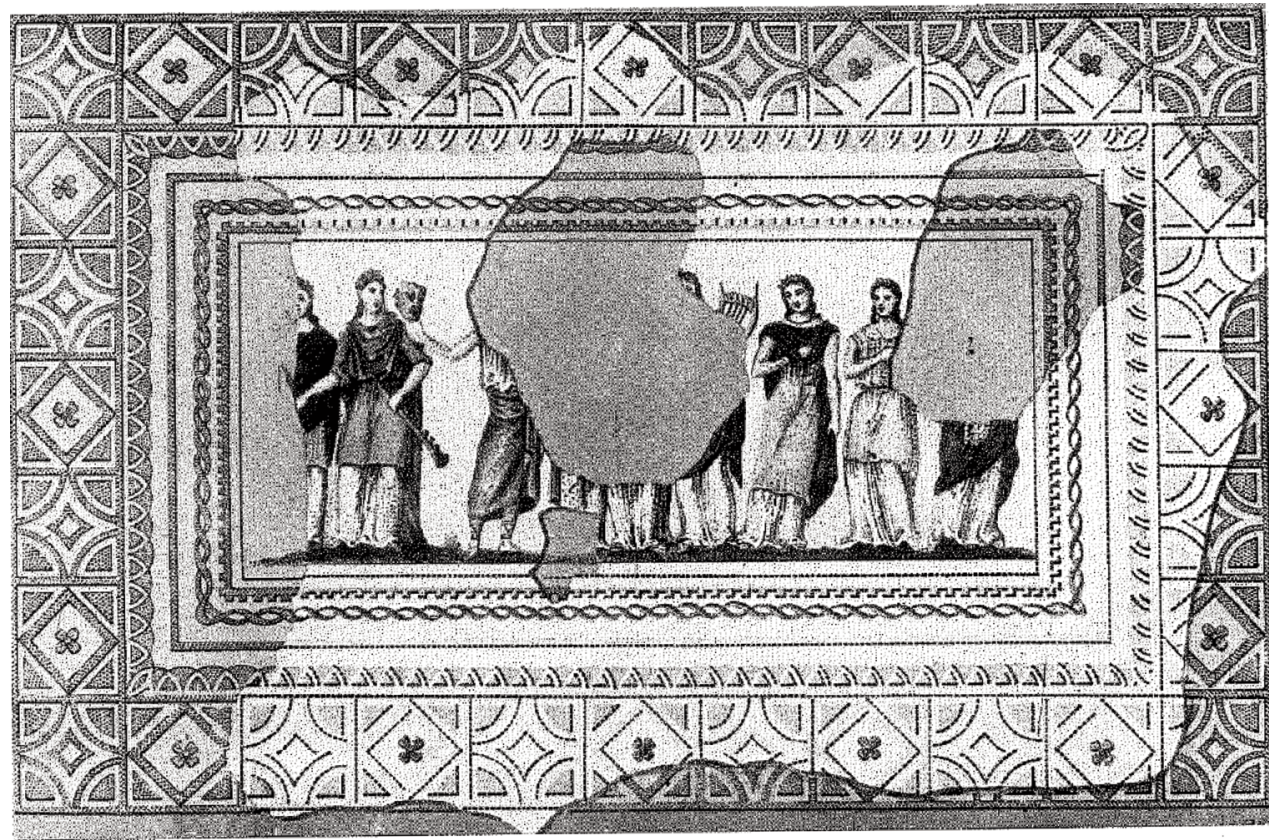

Fig. 10. Mosaico de Itálica. Siglo III

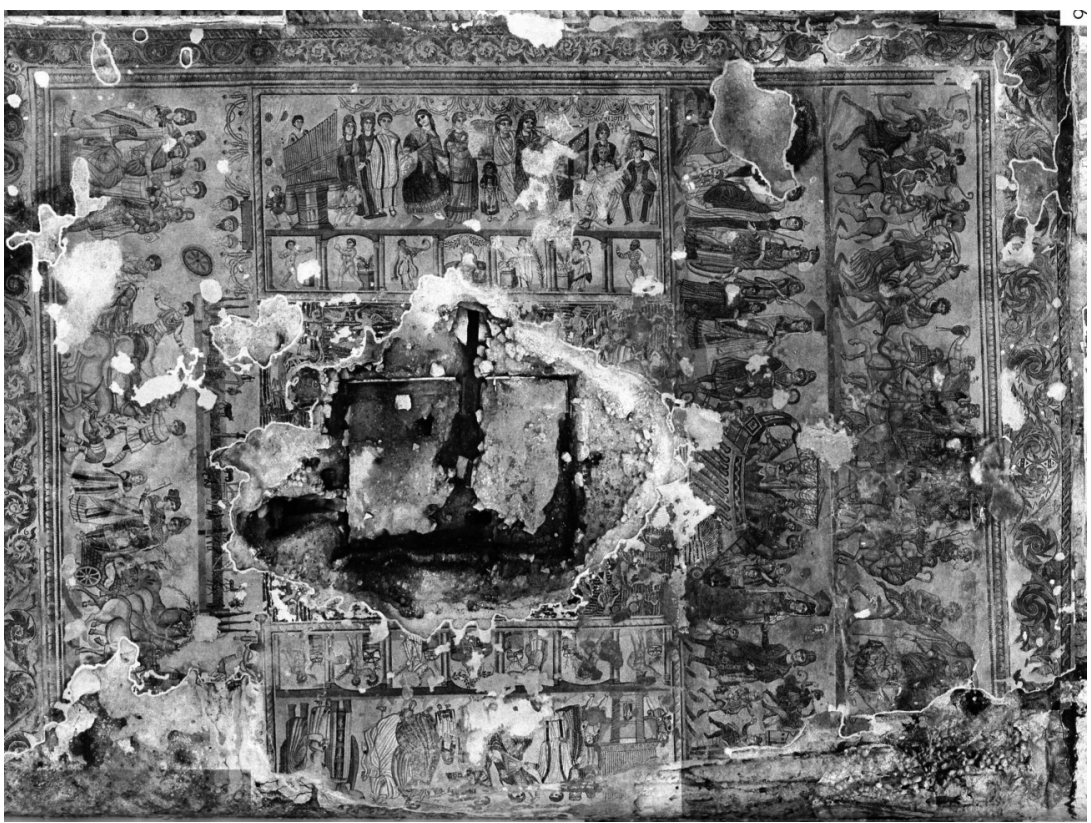

Fig. 11. Mosaico de Noheda, Cuenca. Siglo IV 
También en el gran mosaico de la villa de Noheda, Cuenca, del siglo IV (Fig, 11), aparecen, dentro de una escena de difícil interpretación, en el panel de la zona sur de la fuente central de la estancia principal, Apolo rodeado de las musas Terpsícore y Euterpe con la doble flauta o aulos, y tal vez más alejadas Melpómene y Talía con máscaras de teatro en el rostro, todas ellas visten túnica y manto ${ }^{24}$. Aquí estas musas intervienen como cantoras en esta gran fiesta bajo la dirección de Apolo (Fig. 12).

En la pintura hispanorromana también aparecen las musas acompañadas de Apolo como en la Casa del Obispo,en Gades, de mediados del siglo ${ }^{25}$, en la domus de Tepsícore en Valencia, de mediados del siglo II $^{26}$, y en Bilbilis (Calatayud, Zargoza $)^{27}$.

Igualmente aparecen las musas con Apolo en los sarcófagos hispanorromanos, como el conservado en la catedral de Tarragona ${ }^{28}$

Figuras de musas acompañadas de poetas/sabios; existen cuatro ejemplares.

El mosaico en blanco y negro, de esquema de compás, con orla nilótica y firmado por Seleucus y Anthus, fue hallado el siglo XIX en el triclinium de una casa de Augusta Emerita, fechado en la segunda mitad del siglo II, y se conserva en el Museo de Arte Romano de Mérida. La casa forma parte de una serie de edificaciones urbanas, tal vez una insula, según parece indicar los hallazgos de esta zona de otros mosaicos y pinturas como el de la representación alegórica de Opora ${ }^{29}$. En el levantamiento del pavimento se ocasionaron algunos destrozos pero gracias a antiguos dibujos se pueden conocer con detalles las zonas dañadas ${ }^{30}$. En el me-

24 D. FERNÁNDEZ GALIANO, El triunfo del amor: mosaico de Paris y Helena de Noheda, Cuenca, in M.L. Neira (coord.), Mitología e Historia en los mosaicos romanos, Ed. JC, Madrid 2010, 127, fig. 24; L. LLEDÓ SANDOVAL, Mosaico romano de Noheda (Cuenca): su descubrimiento, Madrid 2010, 145; ID., Mujeres, mitos y arquetipos femeninos en los mosaicos romanos en Noheda, in M.L. Neira (coord. y ed.), Representaciones de mujeres en los mosaicos romanos y su impacto en el imaginario de estereotipos femeninos, CVC, Madrid 2011, 230, figs. 82 y 83.

25 A. CÁNOVAS UBERA y C. GUIRAL PELEGRíN, Las musas de Gades (Cádiz, España), in. C. GUIRAL PELEGRÍN (dir.), Circulación de temas y sistemas decorativos en la pintura antigua, Actas del IX Congreso Internacional de la Association Internationale pour la Peinture Antique (Zaragoza - Calatayud 21-25 septiembre 2004), Calatayud 2007, 487-490 (las musa Melpómene, Clio y la cabeza de otra).

26 A. FERNÁNDEZ DIAZ, Un nuevo ejemplo de personificación de provincia romana en la decoración pictórica de la Domus de Tepsícore (Valencia), in. C. GUIRAL PELEGRíN (dir.), Circulación de temas y sistemas decorativos en la pintura antigua, Actas del IX Congreso Internacional de la Association Internationale pour la Peinture Antique (Zaragoza - Calatayud 21-25 septiembre 2004), Calatayud 2007, 461-465

27 C. BALMELLE et alii, Peintures urbains à I époque julio-claudienne dans lê conuentus Caesaraugustanus et dans la province d Aquitaine, in L Aquitaine et I Hispanie septentrionale à I époque julioclaudienne. Organisation et exploitation des espaces provincinciaux, IV Colloque Aquitania Saintes, septembre 2003, 2006, 253-254, fig.3.

${ }^{28}$ F. de A. ESCUDERO, Mosaicos con musas..., 120

29 G. LÓPEZ MONTEAGUDO, Un nuevo mosaico de Augusta Emerita con la representación de Opora, Assaph 10-11 (Studies in honour of Asher Ovadiah), 2005-2006, 347- 364 ID., Nuevos documentos del mosaico emeritense de Oporas, Anas 19-20, 2006-2007, 185-222.

30 A. BLANCO, Mosaicos romanos de Mérida, CMRI I, Madrid 1978, 30-32, no 9, láms. 12-20. 


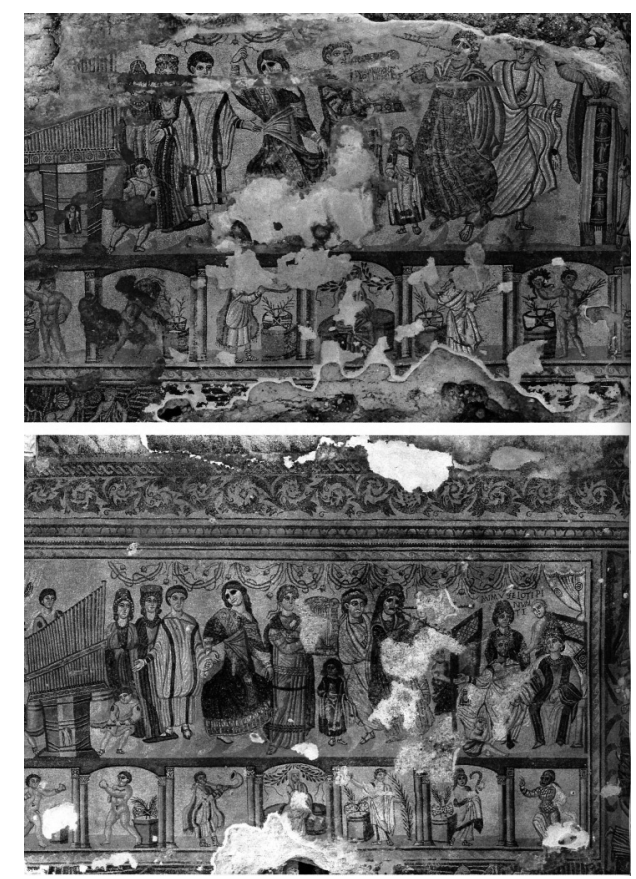

Fig. 12. Detalle del mosaico de Noheda, Cuenca. Siglo IV

dallón central aparece sentado el poeta Teócrito, padre de la poesía bucólica, con cayado en la mano derecha y máscara en la izquierda, junto a la musa Erato, de pie sosteniendo la cítara y el plectro, acompaña al grupo una cabra. En los cuatro medios círculos de la composición se representan las restantes ocho musas en grupo de dos, de pie y con los atributos: Urania con la esfera (como en los mosaicos de Moncada, supra, y Arróniz, infra) y el puntero, Clío con el scrinum lleno de rollos, Melpómene con la máscara trágica, Talía con la máscara cómica. En los ángulos de la cenefa se han representado dos sabios o poetas que bien pudieran ser Moschos o Bíos, Tales o Arato (Fig. 13) ${ }^{31}$.

La composición formada por literato y musa aparece en los mosaicos de Tenuta di Porcareccia, Lorium (Italia) ${ }^{32}$ Casa Arsenal (Casa de Virgilio), Hadrumetum, la actual Sousse (Túnez) ${ }^{33}$, de Monnus en Trier ${ }^{34}$, Taparura (Túnez) ${ }^{35}$, Bulla Regia

${ }^{31}$ G. LÓPEZ MONTEAGUDO- M. P. SAN NICOLÁS PEDRAZ, Los Sabios y la Ciencia..., 91.

32 E. THEOPHILIDOU, Die Musenmosaiken ...,270-271 (Ennius o Menandro, Melpomene y Polimnia).

33 K.M.D. DUNBABIN, The Mosaics of Roman..., 131, 242, 269 (Virgilio, Melpomene y Clío).

${ }^{34}$ K. PARLASCA, Die römische Mosaiken..., 41-43, láms. 42-47; E. THEOPHILIDOU, Die Musenmosaiken...,280-286 (Icaros y Polimnia, Arato y Urania, Cadmos y Clío, Hiagnis y Euterpe).

35 D. PARRISH, Season Mosaics of Roman North Africa, Roma 1984, 218-221, láms. 77-78; E. THEOPHILIDOU, Die Musenmosaiken ..., 326- 329 (Ennius y una musa, tal vez Clío, Polimnia, Caliope, Melpomene o Euterpe). 


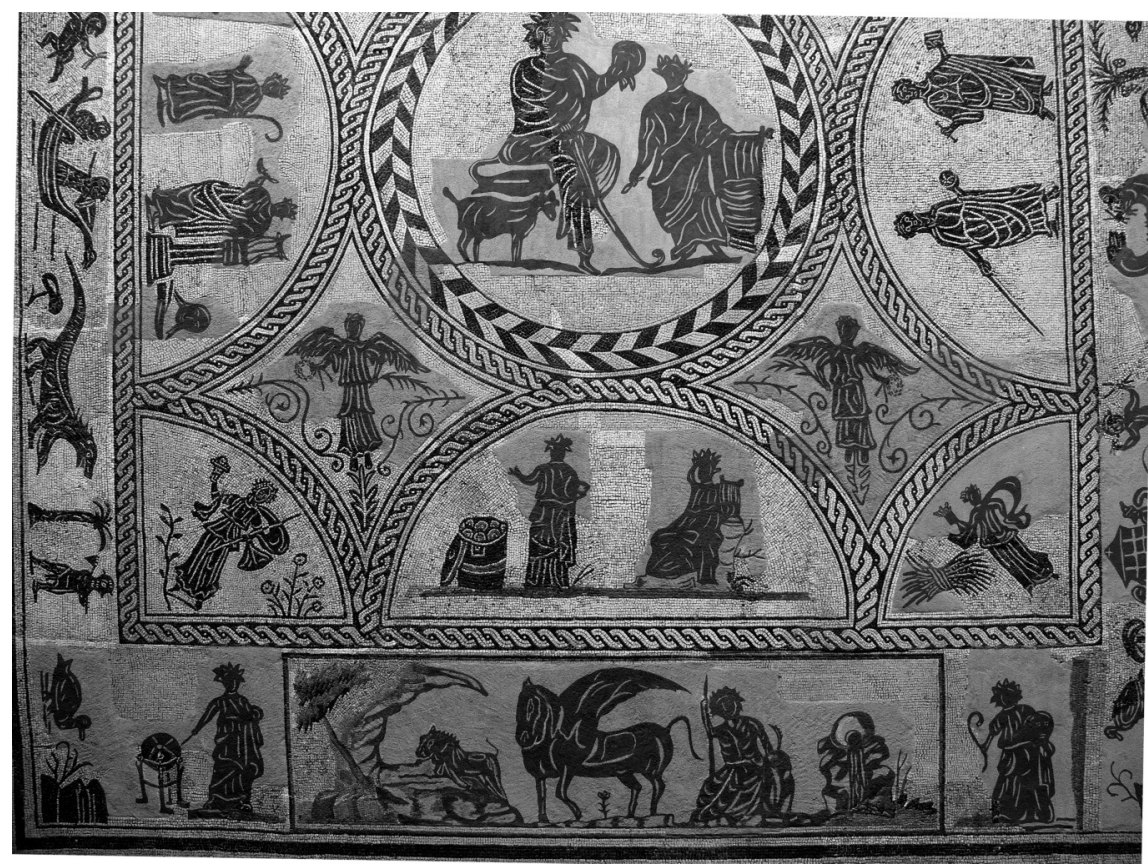

Fig. 13. Mosaico de Augusta Emerita. Siglo II-IV

(Túnez) ${ }^{36}$ y de Vichten ${ }^{37}$, fechados todos en la primera mitad del siglo III y en Hispania en los pavimento de Arróniz (Navarra), Torralba (Huéscar, Granada) y Valencia que posteriormente analizaremos. Mientras que el grupo de musas por parejas se conoce también en el mosaico de los Literatos de Trier, del siglo III $^{38}$. Igualmente aparecen las musas acompañadas de maestros en los sarcófagos hispanorromanos, como el conservado en la catedral de Murcia, el del Museo de Lisboa y el de Belem (Portugal) ${ }^{39}$

En el pavimento de la villa de Arróniz (Navarra), que se conserva en el Museo Arqueológico Nacional y se fecha a fines del siglo III o comienzos del IV ${ }^{40}$ se presen-

36 R. HANOUNE, Une muse et un philosophe sur une mosaïquede Bulla Regia, Mélanges P. Boyancé, Roma 1974, 387-394; E. THEOPHILIDOU, Die Musenmosaiken ...,316-317 (busto de filosofo y las musas)

37 J. KRIER- F. REINERT, Homer und die neun Musen bei den Treverern, Antike Welt 26/3, 1995, 237-238 (En el medallón central Homero y Calíope, y en otros Polimnia, Erato, Terpsícore, Melpómene, Urania, Talía, Clío y Euterpe).

38 K. PARLASCA, Die römische Mosaiken..., 27-28, láms. 26-27; E. THEOPHILIDOU, Die Musenmosaiken ..., 278-279; G. LÓPEZ MONTEAGUDO y M.P. SAN NICOLÁS PEDRAZ, Reflejos de la vida intelectual..., 249-308; ID. Los sabios y la ciencia..., 71-110

39 F. de A. ESCUDERO, Mosaicos con musas..., 120.

40 J.M. BLÁZQUEZ- M.A. MEZQUIRIZ, Mosaicos romanos de Navarra, CMRE Madrid 1985, 15- 22, lám. 50. 
ta una composición octogonal, posiblemente de una estancia señorial de la misma forma. Está dividida en nueve compartimentos, en cada uno de los cuales se ha representado un grupo integrado por un sophos, generalmente en posición sentada y una musa en pie delante de una villa ${ }^{41}$ (Fig. 14): Sector I, Homero y Caliope o Polimnia; sector II, orador y Terpsícore tocando la lira; Eurípides o Menandro y Melpomene tocando la lira; sector IV, Menandro, máximo representante de la comedia nueva, y Talía con máscara; sector V, Hiagnis, inventor del monoaulós que toca la musa, y Euterpe; sector VI, Cadmo, historiador o descubridor de la escritura fenicia, y Clío o Calíope con uolumen y calamus; sector VII no se conserva ninguna figura; sector VIII, Erato; sector IX, Arato, poeta y astrónomo, y Urania portando la esfera (como en Moncada y Mérida) y el radius o compás, como musa de la astronomía y del universo en la filosofía estoica (Platón, Phaedr., 259D; Anthol. Gr., IX, 505; Corn. O.L., XIV, 17,4).

En el deteriorado mosaico de Torralba, Huéscar en Granada, fechado en el siglo IV ${ }^{42}$, aparecen, de izquierda a derecha, dos figuras femeninas, una de ellas con restos de la palla, un espacio en blanco en donde posiblemente estaría representada la lira, como señala M. Gómez Moreno, y a continuación un personaje masculino con pallium. (Fig. 15).

Asimismo en el fragmentario mosaico de Valencia, fechado en el siglo $\mathrm{II}^{43}$ se ha representado en el emblema circular una musa con una lira apoyada en un alto pedestal, acompañada de un sabio del que se conservan los hombros y barbilla. Debajo del grupo existen restos de una inscripción que ha sido identificada por el nombre de Terpsícore (Fig. 16)

En conclusión, el número de mosaicos hispanorromanos (catorce en total) con la representación de Musas es considerable dentro de la musivaria romana, teniendo de particular que existen ejemplares parietales localizados in situ. La cronología de estos mosaicos abarca desde el siglo II hasta el IV, no habiendo diacromías entre los distintos grupos iconográficos de bustos y de cuerpo entero. Se han localizado tanto en las domus como en las villae y, aunque no existe una decoración más o menos establecida para un espacio determinado, se percibe que corresponden a estancias de prestigio como ocurre con el pavimento octogonal de la villa de Arróniz (Navarra), el de Caesaraugusta o el de la Noheda (Cuenca), y cuando se puede identificar la habitación, al triclinium, que se adapta al efecto de la filosofía neoplatónica en donde las musas presiden los banquetes de los filósofos. Todas estas representaciones proyectan lo que el propietario quiere transmitir a sus invitados la imagen de la cultura o el conocimiento total de las ciencias para alcanzar la sabiduría suprema y la gloria como reflejos de la inmortalidad.

41 M.P. SAN NICOLÁS PEDRAZ, Arquitectura rural en los mosaicos hispanos, L Africa Romana XII, 1998, 895-900.

42 M. GÓMEZ MORENO, Miscelánea, Madrid 1949, 375; E. PAREJA- M. SOTOMAYOR, Excavaciones en el yacimiento romano de Torralba en Huéscar (Granada), NAHArq. 6, 1979, 499-522, fig. 7lám. VIIa-b.

43 I. LÓPEZ GARCíA et alii, Hallazgos arqueológicos en el Palau de Les Corts, Valencia 1994, 142156, láms. 32-43; G. LÓPEZ MONTEAGUDO y M.P. SAN NICOLÁS PEDRAZ, Reflejos de la vida intelectual..., 249-308; ID. Los sabios y la ciencia..., 110. 


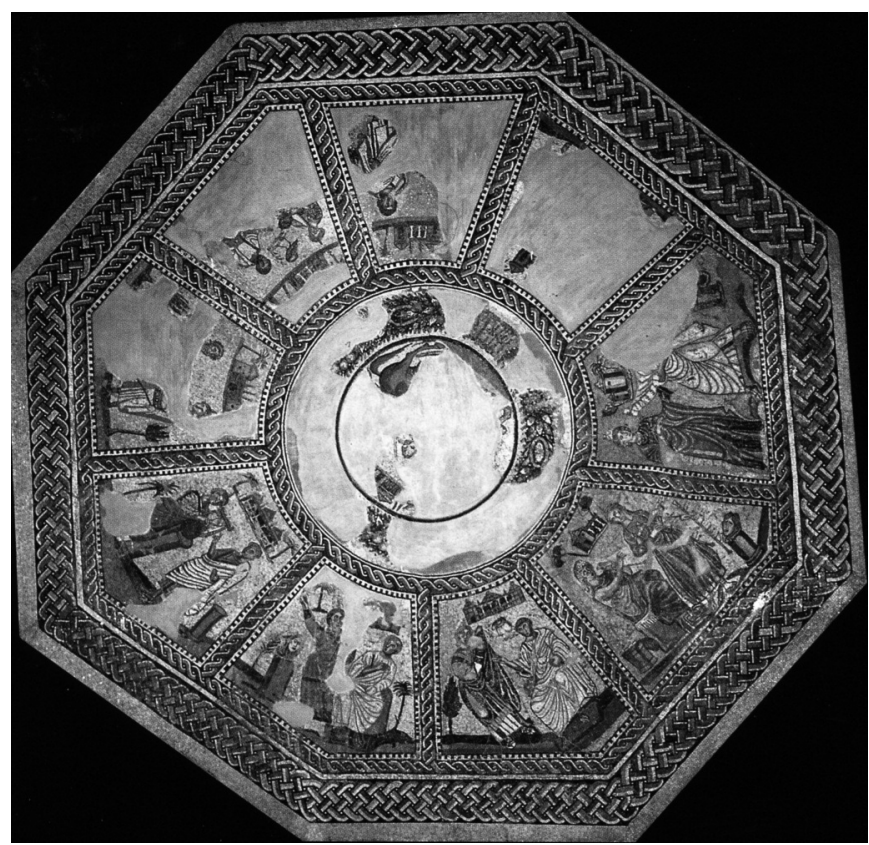

Fig. 14. Mosaico de Arróniz, Navarra. Siglo III-IV (Foto de G. López Monteagudo)

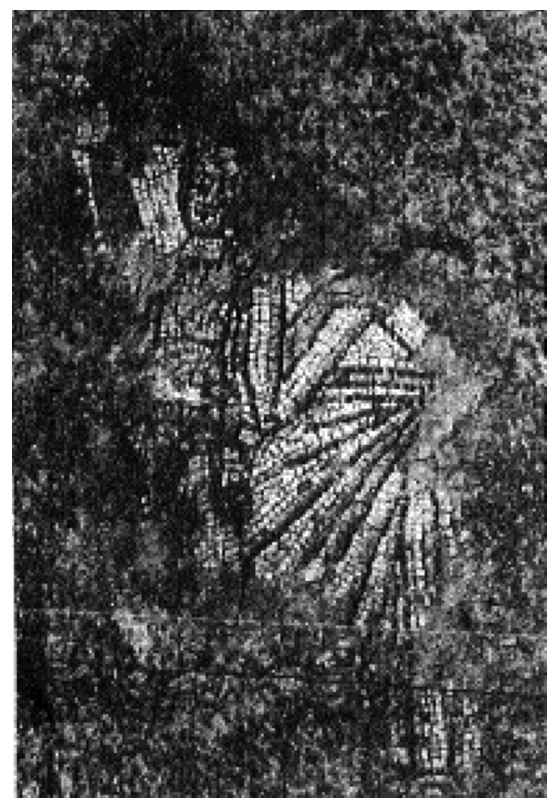

Fig. 15. Detalle del mosaico de Torralba, Huescar, Granada. Siglo IV 


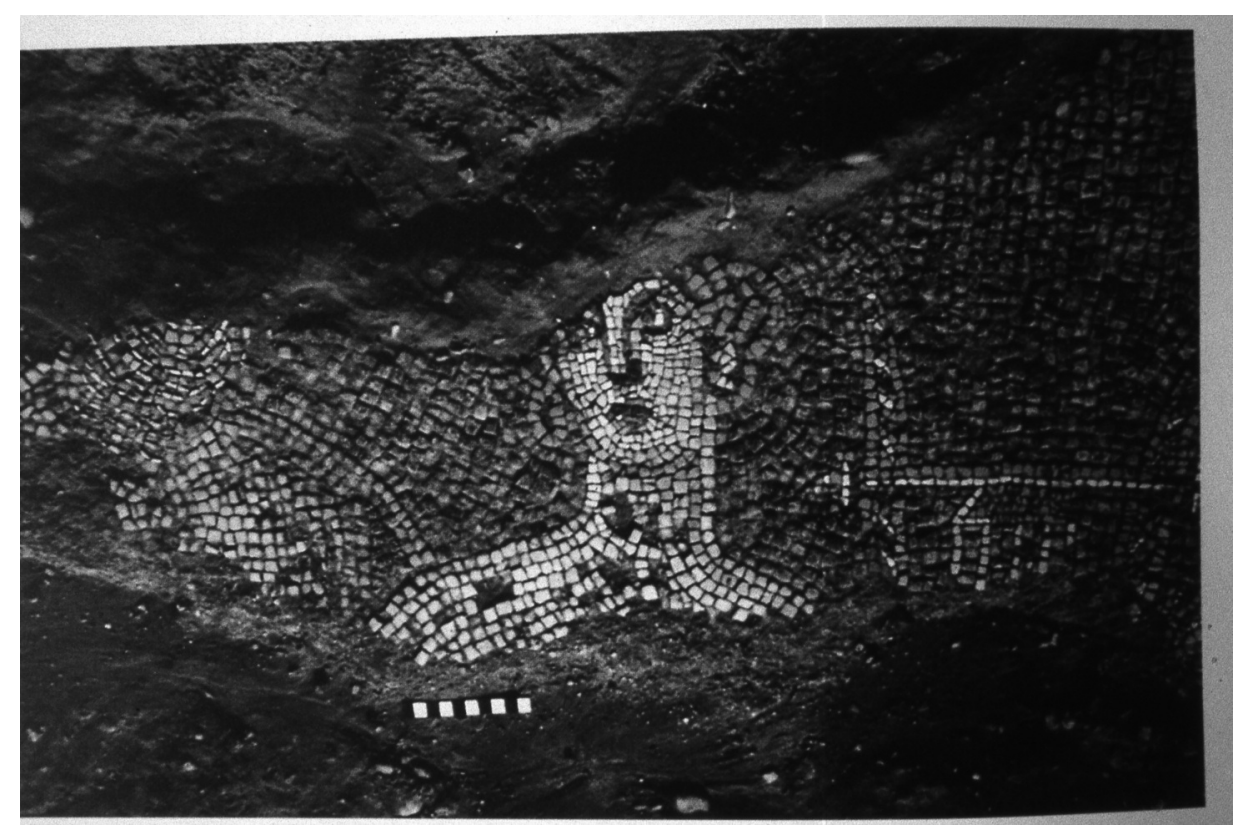

Fig. 16. Mosaico de Valencia. Siglo II

\section{CATÁLOGO}

1. ITÁLICA. Mosaico policromo de circo. Aparecen las nueve musas separadas en sendos círculos en bustos con sus nombres en latín. Triclinium. Siglo IV. Hoy perdido. A. BLANCO FREIJEIRO (1978b), 43, lám. 61-73; S. CELESTINO (1977), 375-381; ; J. LANCHA (1997), 190- 193, o 91, láms. LXXXVII- LXXXIX; G. LOPEZ MONTEAGUDO (2010), 148-151, fig. 188;I. MAÑAS ROMERO (2011), 86-90, lám. XXXII, figs. 185, 187 y 188. p. 25-26, n. 1, láms. 1-7.

2. MONCADA, VALENCIA. Mosaico policromo de la villa de Pouaig con las nueve musas. Se encuentran dentro de nueve recuadros, en bustos y están identificadas con sus nombres en latín. Siglo III. Museo de Prehistoria de Valencia. A. BALIL y T. MAÑANES (1980), 19-30; J. GÓMEZ PALLARÉS (1997), 159- 160, lám. 67; J. LANCHA (1997), 151-153, nº 76, lám. LXVII; T. PASIES OVIEDO (2004), 222-229.

3. CAESARAUGUSTA. Fragmento de un mosaico policromo del triclinium de la Casa de Orfeo de Caesaraugusta. En un ángulo aparece el busto de la musa Clío con túnica y diadema de plumas, mirando a la derecha y flanqueada porun stylus y unas tablillas de cera para escribir (diptychon). En uno de los hexágonos, muy destruido, del emblemata aparece restos de una esfera, símbolo de Urania, mientras que otro se conserva el busto de un sátiro. Siglo II. Museo Arqueológico de Zaragoza. F. de A. ESCUDERO (1998-1999), 109-132, láms. 2,2 y 5,2. 
4. ALTAFULLA (TARRAGONA). Mosaico policromo parietal de la villa de Els Munts, realizado con opus vermiculatum y fijado sobre un soporte cerámico como marco, de forma cuadrangular por los dos lados, conservando restos de pintura. Aparece el busto de Euterpe con tocado de pluma y los auloi. Siglo II. Museo Arqueológico de Tarragona, F. TARRATS et alii, (1999), 197-225 (216); M. DURÁN PENEDO (2000), 35-51. VV.AA. (2001), 170-171.

5. ALTAFULLA (TARRAGONA). Mosaico policromo parietal de la villa de Els Munts, realizado con opus vermiculatum y fijado sobre un soporte cerámico de forma cuadrada en el exterior y circular en el interior como marco. Aparece el busto de Talía con tocado de pluma y con la máscara teatral de la comedia en la parte inferior derecha. Siglo II. Museo Arqueológico de Tarragona, F. TARRATS et alii, (1999), 197-225 (216); M. DURÁN PENEDO (2000), 35-51. VV.AA. (2001), 170-171.

6. ALTAFULLA (TARRAGONA). Mosaico policromo parietal de la villa de Els Munts, realizado con opus vermiculatum y fijado sobre un soporte cerámico como marco. Aparece el busto de Mnemosine/ Polymnia/ Apolo, con diadema blanca y sin atributo Siglo II. Museo Arqueológico de Tarragona, F. TARRATS et alii, (1999), 197-225 (216); M. DURÁN PENEDO (2000), 35-51. VV.AA. (2001), 170-171.

7. MONTEMAYOR (CÓRDOBA). Fragmentos de un mosaico policromo de Montemayor (Córdoba), la antigua Ulia. Dos fragmentos de mosaicos con cabezas de musas en busto; en uno de ellos figuraba la cabeza y hombros de Euterpe, identificada con su nombre en latín y en el otro fragmento dos cabezas femeninas. Perdido. Siglo IV. J.M. BLÁZQUEZ (1981), 56.; G. LÓPEZ MONTEAGUDO y M.P. SAN NICOLÁS PEDRAZ (1994), 249-308; G. LÓPEZ MONTEAGUDO y M.P. SAN NICOLÁS PEDRAZ (1996), 71-110; J. LANCHA (1997), 200, no 100.

8. MONFORTE (PORTUGAL). Mosaico policromo dionisiaco de la villa de Torre de Palma, de forma rectangular con las nueve musas, anepigrafas, de cuerpo entero, en pie, con túnicas y palla. Tablinum. Época constantiniana. Museo Nacional de Arqueología y Etnografía de Lisboa J.M. BLÁZQUEZ (1980), 8, fig. 3; J. LANCHA (1997), 231- 255, nº 109, láms. CIX- CXI, L y M.

9. ITÁLICA. Mosaico policromo con las nueve musas, de cuerpo entero y en pie, con túnicas y palla y carente de letreros identificativos, rodeando a una figura central muy deteriorada, posiblemente Apolo. Siglo III, hoy perdido. M.P. SAN NICOLÁS PEDRAZ (1991), 531-540; J. LANCHA (1997), 193-195, no 92, lám. XC; I. MAÑAS (2008); G. LÓPEZ MONTEAGUDO (2010), 143-144, fig. 182.

10. NOHEDA (CUENCA). Gran mosaico policromo de la villa de Noheda. En el panel de la zona sur de la fuente central de la estancia principal, aparece Apolo rodeado de las musas Terpsícore y Euterpe, y tal vez más alejadas Melpómene y Talía. Siglo IV. J.L. LLEDÓ SANDOVAL (2010), 145; D. FERNÁNDEZ Galiano (2010), 127, fig. 24; J.L. LLEDÓ SANDOVAL (2011), 230, figs. 82 y 83.

11. AUGUSTA EMERITA. Mosaico en blanco y negro, de esquema de compás, firmado por Seleucus y Anthus. En el medallón central aparece sentado el poeta 
Teócrito junto a la musa Erato, y en los cuatro medios círculos de la composición se representan las restantes ocho musas en grupo de dos, de pie y con los atributos: Urania, Clio, Melpómene y Talía. En los ángulos de la cenefa se ha representado dos sabios o poetas. Triclinium. Segunda mitad del siglo II. Museo de Arte Romano de Mérida. A. BLANCO FREIJEIRO (1978a), 30-32, no 9, láms. 12-20; G. LÓPEZ MONTEAGUDO y M. P. SAN NICOLÁS PEDRAZ (1996), 91. J. LANCHA (1997), 213- 218, nº 105, láms. XCIX- Cl.

12. ARRÓNIZ (NAVARRA). Mosaico policromo de forma octogonal, posiblemente de una estancia señorial de la misma forma. Está dividida en nueve compartimentos, en cada uno de los cuales se ha representado un grupo integrado por un sophos y una musa. Finales del siglo III o comienzos del IV. Museo Arqueológico. J.M. BLÁZQUEZ- M.A. MEZQUIRIZ (1985), 15- 22, lám. 50; J. LANCHA (1997), 178- 183, no 87, láms. LXXVII- LXXXI; M.P. SAN NICOLÁS PEDRAZ (1998), 895-900.

13. TORRALBA, HUESCAR (GRANADA). Mosaico policromo de una villa con dos musas muy deterioradas y un personaje masculino con pallium. Siglo IV, (Fig. 12). M. GÓMEZ MORENO (1949), 375; E. PAREJA y M. SOTOMAYOR (1979), 499-522, fig. 7lám. VIla-b. J. LANCHA (1997), 163- 164, no 81 bis, lám. LXX.

14. VALENCIA. Fragmento de mosaico policromo hallado en el Palau de les Corts. Casa de Terpsicore. En el emblema circular una musa acompañada de un sabio. Debajo del grupo existen restos de una inscripción que ha sido identificada por el nombre de Terpsicore. Siglo II. I. LÓPEZ GARCÍA et alii (1994), 142-156, láms. 3243; G. LÓPEZ MONTEAGUDO y M.P. SAN NICOLÁS PEDRAZ (1996), 110.

\section{BIBLIOGRAFÍA DEL CATÁLOGO}

BALIL, A. y MAÑANES, T. (1979): Mosaico con representaciones de las nueve Musas, hallado en Moncada (Valencia), Boletín del Seminario de Estudios de Arte y Arqueología 45, 19-30. Y en (1980) Estudios sobre mosaicos romanos, VII SA, Valladolid.

BLANCO FREIJEIRO, A. (1978a): Mosaicos romanos de Mérida, CMRI I, Madrid.

BLANCO FREIJEIRO, A. (1978b): Mosaicos romanos de Itálica, CMRE II, Madrid.

BLÁZQUEZ, J.M. (1980): Los mosaicos romanos de Torre Palma (Monforte, Portugal), AEspA 53, 1980, 125-162.

BLÁZQUEZ, J.M. (1981): Mosaicos romanos de Córdoba, Jaén y Málaga, CMRE, Madrid.

BLÁZQUEZ, J.M. y MEZQUIRIZ, M.A. (1985): Mosaicos romanos de Navarra, CMRE, Madrid 1985, 15-22, lám. 50.

CELESTINO, S. (1977): Mosaicos perdidos de Itálica, Habis 8, 375-381.

DURÁN PENEDO, M. (2000): Nuevos mosaicos de la villa dels Munts en Altafulla, Tarragona. Apreciaciones iconográficas, Monte Catano 3, 35-51.

ESCUDERO, F. de A. (1998-1999): Mosaico con musas de la "Casa de las Murallas" de Zaragoza, Anas 11-12, 109-132, láms. 2,2 y 5,2.

FERNANDEZ GALIANO, D. El triunfo del amor: mosaico de Paris y Helena de Noheda, Cuenca, in M.L. Neira (coord.), Mitología e Historia en los mosaicos romanos, Ed. JC, Madrid 2010, 127.

GÓMEZ MORENO, M. (1949): Miscelánea, Madrid. 
GÓMEZ PALLARÉS, J. (1997): Edición y comentario de las inscripciones sobre mosaicos de Hispania. Inscripciones no cristianas, Roma.

LANCHA, J. (1997): , Mosaïque et culture en occidente Dans I occident romain, I-IV siècle, Roma.

LÓPEZ GARCíA, I. et alii (1994): Hallazgos arqueológicos en el Palau de Les Corts, Valencia 1994.

LÓPEZ MONTEAGUDO, G. Otras mitologías, in P. LEÓN (coord.), Arte romano de la Bética. Mosaico. Pintura. Manufacturas, Fundación Focus-Abengoa, Sevilla 2010, 143-151

LÓPEZ MONTEAGUDO, G. y SAN NICOLÁS PEDRAZ, M.P. (1994): Reflejos de la vida intelectual en la musivaria romana, Espacio, Tiempo y Forma II/7, 1994, 249-308.

LÓPEZ MONTEAGUDO, G. y SAN NICOLÁS PEDRAZ, M.P. (1996): Los Sabios y la Ciencia en los mosaicos romanos, $L$ Africa Romana $X I, 71-110$.

LLEDÓ SANDOVAL, J.L. Mosaico romano de Noheda (Cuenca): su descubrimiento, Madrid 2010.

LLEDÓ SANDOVAL, J.L. Mujeres, mitos y arquetipos femeninos en los mosaicos romanos en Noheda, in M.L. Neira (coord. y ed.), Representaciones de mujeres en los mosaicos romanos y su impacto en el imaginario de estereotipos femeninos, CVC, Madrid 2011, 225-238.

MAÑAS ROMERO, I. (2008): Pavimentos decorativos de Itálica (Santiponce, Sevilla), Tesis Doctoral, Univ. Complutense, Madrid.

MAÑAS ROMERO, I (2011): Mosaicos romanos de Itálica (II), CMRI XIII, Madrid.

PAREJA, E. y SOTOMAYOR, M. (1979): Excavaciones en el yacimiento romano de Torralba en Huéscar (Granada), NAHArq. 6, 1979, 499-522.

PASIES OVIEDO, T. (2004): Pavimentos musivos de época romana en la Comunidad Valenciana. Tratamientos y problemáticas asociadas a su conservación y restauración. Tesis Doctoral, Valencia.

SAN NICOLÁS PEDRAZ, M.P. (1991): Sobre el mosaico perdido de Galatea, Itálica (Sevilla), Arte, sociedad, economía y religión durante el Bajo Imperio y la Antigüedad Tardía VIII, Murcia, 531-540

SAN NICOLÁS PEDRAZ, M.P. (1998): Arquitectura rural en los mosaicos hispanos, L Africa Romana XII, 895-900.

TARRATS, F. et alii (1999): Excavaciones a I Área residencial de la Vil.la romana dels Munts (Altafulla, Tarragonès, Empuries 51,197-225.

VV.AA. (2001): Mosaico Romano de Mediterráneo, Madrid. 